\title{
On the role of satellite communications for emergency situations with a focus on Europe*
} \author{
Laurent Franck ${ }^{1, *, \dagger}$,
Matteo Berioli ${ }^{2}$, Philippe Boutry ${ }^{3}$, Guy Harles ${ }^{4}$, \\ Luca Simone Ronga ${ }^{5}$, Rosalba Suffritti ${ }^{5}$ and Laurent Thomasson ${ }^{3}$ \\ ${ }^{1}$ TELECOM Bretagne/site of Toulouse, Toulouse, France \\ ${ }^{2}$ Deutsches Zentrum für Luft- und Raumfahrt (DLR), Weßling, Germany \\ ${ }^{3}$ EADS Astrium, Toulouse, France \\ ${ }^{4}$ SES Astra, Betzdorf, Luxembourg \\ ${ }^{5}$ CNIT/University of Firenze, Firenze, Italy
}

\begin{abstract}
SUMMARY
In this paper, we describe how satellite communications may contribute to disaster management. During emergency situations, satellite communications present many advantages in supporting or replacing a terrestrial infrastructure (if any) subject to destruction or saturation. However, devising the right deployment model deserves close scrutiny in order to fit the responders' needs and sustain financial viability. After reading the paper, we expect that the answers to the following questions will be made clear: what are the roles of telecommunications in emergency situations? How can satellite technologies help? How to mitigate the cost of deploying and using satellite facilities? Who are the actors currently involved in emergency telecommunications and more specifically satellite-assisted emergency telecommunications? Copyright (C) 2011 John Wiley \& Sons, Ltd.
\end{abstract}

KEY WORDS: disaster management; satellite communications

\section{OBJECTIVES AND TARGET AUDIENCE}

Addressing emergency telecommunication systems without taking into account actual emergency field practice is likely to miss the objective. Therefore, Section 2 starts by defining what is understood by emergency situations and what are the key guidelines for deploying emergency telecommunication. In Section 3, we detail the roles of emergency telecommunication. The challenges and stakes impacting the deployment of these telecommunication infrastructures are described in Section 4. In Section 5, the role of satellite communications is extensively discussed, pinpointing the strengths and weaknesses of this technology. The institutions and projects currently active are described in Section 6 with a focus on Europe where there is a rising will to set up a European co-ordinated civil protection effort. Section 7 addresses the issue of financial feasibility and identifies several paths to it. Section 8 lists what are the future directions of R\&D on satellite communications for emergency. Finally, Section 9 concludes by providing a list of what we shall name flawed popular wisdom.

This paper has been contributed both by experts from satellite communications and from emergency operations, therefore ensuring a representative coverage of the subject. We expect it

\footnotetext{
*Correspondence to: Laurent Franck, TELECOM Bretagne/site of Toulouse, Toulouse, France.

†E-mail: Laurent.Franck@ telecom-bretagne.eu

*A white paper produced by the SHARPS working group of the Public Safety Communication Europe Forum. With contributions from: ETSI SES-SatEC working group.
} 
to be a useful primer on the topic for a wide range of readers. Users of emergency telecommunications will learn about the future technical developments, giving them the opportunity to provide valuable feedback. Industry representatives will find here material in order to better understand the challenges driving the market of emergency telecommunications. Researchers will derive from our conclusions some guidelines for future activities. Finally, this contribution is also targeted at political bodies: regional, national and European. Indeed, we strongly believe that they are the key progress-enablers in this field.

\section{SCOPE, DEFINITIONS AND KEY PRINCIPLES}

This paper deliberately focuses on emergency response. To put this term in a time context, emergency response starts from the very first second after the disaster and may last from a couple of hours to several days depending on the event. The emergency phase bears obvious relations with earlier disaster mitigation, preparedness and alerting phases [1] where systems similar to the one discussed here can also be used (e.g. during the preparedness phase, telecommunication equipments can be pre-positioned and stocked in order to enable rapid deployment when necessary). There are also strong links with the post-disaster relief phase because telecommunication systems used during emergency situations could-technically speaking - replace the destroyed infrastructures.

Assuming a focus on emergency response, emergency telecommunications are here defined as the telecommunication facilities used during the emergency response in order to support emergency operations and mitigate the humanitarian and economical impacts of the disaster.

This last decade has witnessed the occurrence of several disasters listed in Table I.

Regardless of their origin (man made, industrial or natural), these catastrophic events may be classified as 'catastrophe with limited impact' and 'catastrophe beyond response means'. Falling in one category or the other depends on whether regional response forces are able to cope with the situation or not. This is typically determined from a combination including but not restricted to the nature of the event, the number of victims and size of the operation field. The hurricane Katrina and the Indian Ocean tsunami are examples of a catastrophe beyond response means.

Three key principles should be considered in designing a solution for emergency telecommunication systems:

1. Regardless of the scope and category, a common and modular emergency telecommunication architecture must be used;

2. Devising an emergency telecommunication system with solely catastrophes beyond means in mind is a mistake because such situations are so exceptional that they do not yield representative design guidelines;

Table I. Examples of recent disaster events.

\begin{tabular}{lll}
\hline Year & \multicolumn{1}{c}{ Type } & \multicolumn{1}{c}{ Place } \\
\hline September 2001 & Terrorist attack & U.S.A (New York) \\
September 2001 & Chemical plant explosion & France (Toulouse) \\
August 2002 & Floods & Central Europe \\
March 2004 & Terrorist attack & Spain (Madrid) \\
December 2004 & Earthquake/tsunami & Indian Ocean region \\
July 2005 & Terrorist attack & U.K. (London) \\
August 2005 & Hurricane & U.S.A. (Louisiana and south east region) \\
April 2006 & Floods & Central Europe \\
July 2007 & Forest fires & Canary Islands \\
August 2007 & Forest fires & Greece \\
October 2007 & Forest fires & U.S.A. (California) \\
May 2008 & Hurricane & Myanmar \\
May 2008 & Earthquake & China (Sichuan) \\
April 2009 & Earthquake & Italy (L'Aquila) \\
January 2010 & Earthquake & Haiti \\
\hline
\end{tabular}


3. As shown in Table I, disasters know no borders, so cross-border operations must be considered as a usual situation stressing the need for common practices and interoperable equipments.

This contribution covers two types of emergency telecommunication infrastructures: (a) a global system to be deployed over Europe in the framework of a prepared and co-ordinated European effort and (b) a small-scale emergency telecommunication systems ready for deployment on specific call for assistance in Europe or abroad.

The first category yields both political and technical challenges and is deeply rooted in the strategy of a European civil protection. However, as advocated in Section 7, global systems provide a unique opportunity to design a cost-wise, integrated and effective approach to emergency communications.

The second category includes small-scale systems like EMERGESAT, TRACKS, MESA and WISECOM. These are good examples of systems providing 'generic' telecommunication support. The ETSI SatEC initial report refers to them as Easily DEployable Communication Cells [1]. One possible application for such systems is the consular flying squads identified in Michel Barnier's report [2]. These systems can also be considered as the building blocks of a larger-scale system.

The two categories have their own financial implications. Indeed, for the first category, there is an important economical risk of spending large amounts of money in provisioning a system with large overcapacity. The second category is by definition less prone to scale savings. A continuum exists ranging from specific solutions with no potential of scale savings to infrastructures shared with other applications.

\section{ROLES OF AN EMERGENCY TELECOMMUNICATION ARCHITECTURE}

The organization of an emergency response encompasses diverse aspects such as: what is done at what time, which institution is taking the lead on a given mission and what is the chain of command. Reports addressing the aftermaths of recent emergency responses frequently pinpoint the role of telecommunications as a corner stone for the organization of an effective response.

It is of chief importance to map the telecommunication architecture onto the response organization and not the other way round. There are - at least - two good reasons:

- Emergency response practices rely heavily on prior training of the responders so to impair the negative effects of stress and often chaotic operation conditions. Modifying the operating modes therefore compromise prior training and possibly call for heavily reconsidering it. There is a risk to fall into a permanent state of motion where technology could drive field practices at the expense of effectiveness and co-ordination.

- The way of organising emergency response is usually governed by national or regional laws; modification of these laws is a complex and lengthy process.

It is important to emphasise that presently the telecommunication market is often technology driven. Because of the reasons mentioned before, an opposite stance must be adopted: the telecommunications solutions must be primarily driven by the user needs (still paying attention not to rule out innovation by excess of virtue).

Two interleaved perspectives exist when considering the position of emergency telecommunication systems:

- The system perspective where the focus is put on the organizational entities taking part to the telecommunication network and how telecommunication help these entities to cooperate effectively.

- The service perspective where the focus is put on the application and type of data supported by the network. 
These two perspectives are further detailed below.

\subsection{The system perspective}

The organization of the chain of command during emergency response differs from country to country. However, the global organizations are comparable: the operation is made of multiple missions co-ordinated at a multi-stage level. Figure 1 (inspired by [3]) shows a typical organization deployment together with the communication flows. The organization is basically dispatched around three poles: field (where the disaster event took place), near field and back. (Near-) field structures are put in place for field disaster management purposes and shut down afterwards. Back structures are the same structures as used for daily operations plus an optional temporary co-ordination task force set up for the sake of efficient co-ordination among various disciplines (fire fighting, medical care, law enforcement, etc.) and the authorities.

Figure 1 depicts the operation organization once fully deployed. For various reasons ranging from equipment availability to journey time, the organization is never deployed at once but rather incrementally. So are the telecommunication infrastructures that must be operative whatever the deployment stage and operation scale. For example, at the very beginning, scouting teams are dispatched on the field. Such teams assess the situation, directly coordinating with the authorities at the back.

When following a chain of command (from the bottom of Figure 1 to the top), one can see that several concurrent paths are present. This complexity stems from the difference between operational authority and employer authority. For example, the field emergency control centres have to report to the field task for co-ordination (operational authority) but also their respective (back) control centres (employer authority). This is a driver for using interoperable, standard based equipment. Also, the principle of chain of command must be enforced by the telecommunication network, preventing as much as possible communications not conforming to the implemented chain.

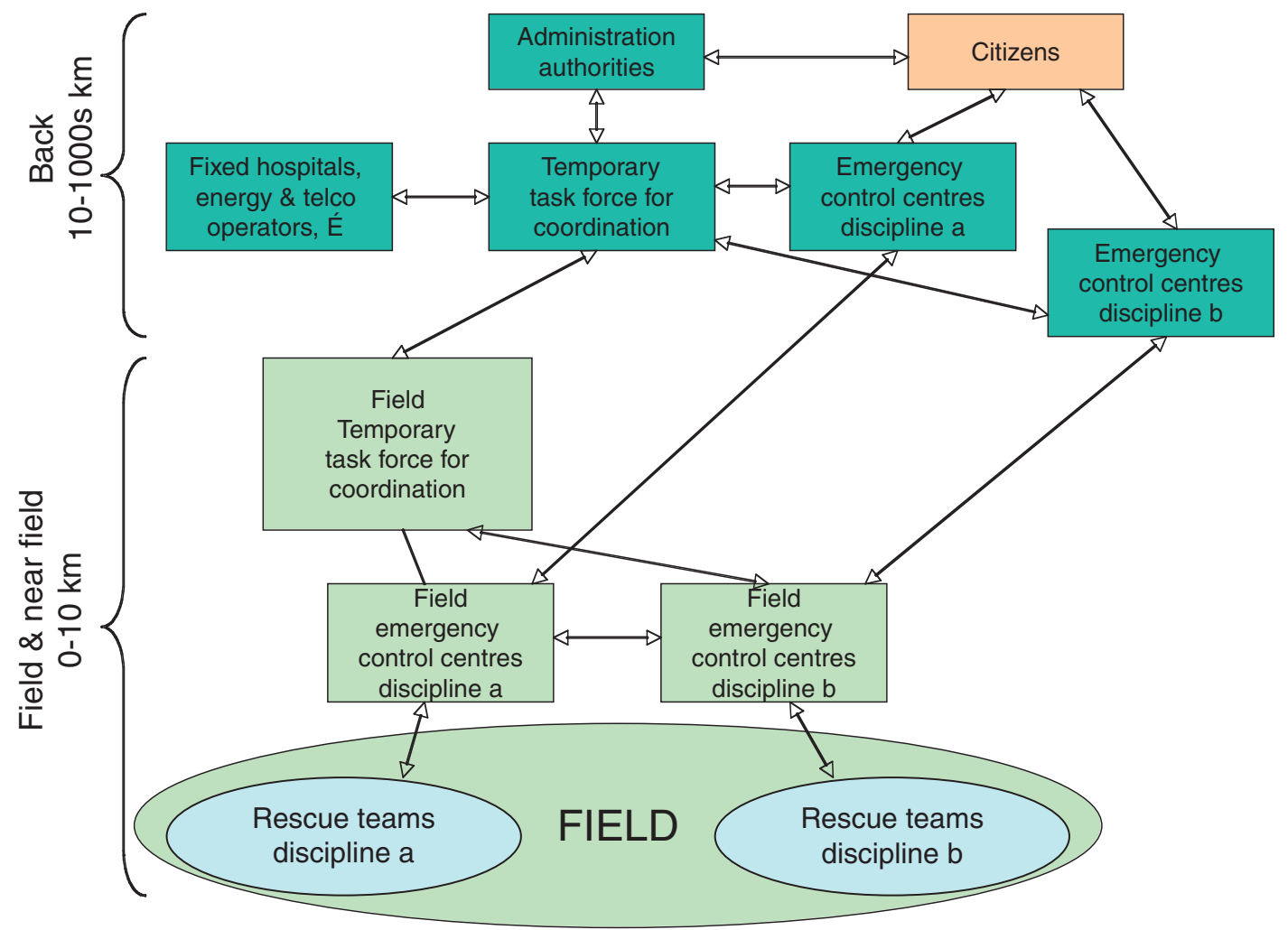

Figure 1. Typical emergency operation organization. 
Table II. Inventory of services.

\begin{tabular}{|c|c|c|}
\hline Category & Examples of service & Characteristics \\
\hline $\begin{array}{l}\text { Personal com- } \\
\text { munications }\end{array}$ & $\begin{array}{l}\text { Telemedicine, voice communication, interactive } \\
\text { |mapping during scouting }\end{array}$ & $\begin{array}{l}\text { Message-based or stream- } \\
\text { based }\end{array}$ \\
\hline GMES & $\begin{array}{l}\text { Digital added value maps, tracking of forest } \\
\text { fires }\end{array}$ & Real-time or non real-time \\
\hline $\begin{array}{l}\text { Navigation and } \\
\text { localization }\end{array}$ & Team tracking, victim localization & $\begin{array}{l}\text { Narrowband or broadband } \\
\text { trunking or backhauling }\end{array}$ \\
\hline $\begin{array}{l}\text { Data broadcast- } \\
\text { ing }\end{array}$ & $\begin{array}{l}\text { Broadcasting of security information (keys, } \\
\text { biometric fingerprints, security policies), distri- } \\
\text { bution of hi-definition maps }\end{array}$ & $\begin{array}{l}\text { Unicast, multicast, broadcast } \\
\text { or anycast }\end{array}$ \\
\hline Intra-networking & $\begin{array}{l}\text { Ad hoc network connectivity repairing, distri- } \\
\text { bution of ad-hoc routing information, Analog } \\
\text { PMR/GSM/ } \\
\text { TETRA/WIMAX backhauling }\end{array}$ & $\begin{array}{l}\text { Simplex, half-duplex or full } \\
\text { duplex }\end{array}$ \\
\hline Inter-networking & Data trunking, Internet access, VPN & Interactive or non-interactive \\
\hline
\end{tabular}

The framework in Figure 1 supports missions of several types such as first aid and medical care, psychological assistance, emergency lodging/sheltering, water sanitization, food/medicine supply. Operation co-ordination can also be considered as a specific mission supporting the complete operation.

Each mission displays specific needs in term of communication capabilities. These needs are expressed according to:

- The time of occurrence and typical duration of the mission.

- The number and location of the users: field, near field and back.

- The mobility requirements (fixed, transportable, mobile).

- The services deployed.

\subsection{The service perspective}

Nowadays, the service which is most used is voice transmission via analogue radios and to a lesser extent low rate (several kbit/s) data transmission (e.g. facsimile transmissions). Indeed, analogue PMR (Private Mobile Radio) is a popular technology among responders providing affordable, robust and autonomous communication devices. Security and safety forces in Europe are currently shifting to digital PMR (mostly TETRA based). While digital PMR makes it possible to enhance the security (authentication, integrity, confidentiality) of communications, the implemented data rates are still in the range of several tens of $\mathrm{kbit} / \mathrm{s}$. The net result is a strong limitation of the available bandwidth hence limited development and deployment of truly ICT supported emergency response. There are certain cases where satellite-based communications are used but the present pricing of both the equipment and the capacity prevent frequent use.

Regardless of the present constraints, it is possible to inventory the services in an emergency context (Table II).

\section{CHALLENGES AND STAKES OF EMERGENCY TELECOMMUNICATIONS}

As described earlier, it is important to devise a proper mapping between the emergency telecommunication architecture and the organization. In the following paragraphs, we list the various challenges awaiting emergency telecommunication designers. The section ends with an overview of the stakes of emergency response.

\subsection{Challenges}

Experienced operation managers agree on the fact that every operation is specific. Weather conditions, the nature of the event, place and time of occurrence put unexpected constraints on 
the organization of the response. For example, during the AZF chemical plant explosion, a significant number of car drivers abandoned their vehicles on the spot, making it difficult for the responders to reach the rescue scenes or their brigades. This certainly complicated the management of human resources and called for extra co-ordination among the participating institutions.

This high potential of randomness leads to two conclusions: (1) while planning and training are important, flexibility is definitely the keyword and (2) flexibility can only be achieved through ubiquitous communication capabilities among the different operation actors.

Similarly, it has often been witnessed that initial scene reports are flawed, if not missing. Having at hand accurate information is the key to effective management in order to dispatch initial (and often scarce) forces at the right place and anticipate the need for support. From the previous discussion it appears that the emergency telecommunication must be rapidly deployable, rapidly meaning here in the first $10 \mathrm{~min}$ after the event. These are not the only constraints.

The needs and characteristics of the emergency response evolve with time in terms of personnel and equipment engaged. Telecommunication needs are also likely to evolve as time goes by, resulting in an increased network size and bandwidth demand. Additional services are also likely to be deployed. Incremental deployment and scalability are therefore mandatory properties of the proposed architecture. As the on-field telecommunication infrastructure will be deployed incrementally or be available with limited capacity, the applications and underlying network protocols must either be able to cope with temporary shortage of connectivity or to seamlessly switch to another technology offering global coverage, enhanced resources, etc (e.g. WIMAX to satellite vertical handover).

Emergency response management is often cross-institutional (fire brigades, police departments, emergency medical care, first aid organization, etc.). Beside the different field practices, it also means disparate equipment (at best different brands) and technical skills for the set up and use of telecommunication equipments. It is therefore important to promote standardbased telecommunication infrastructures in order to guarantee interoperability and possibly pooling of resources.

Last but not least, the need for security (in its computer and network understanding) must not be underestimated. Confidentiality provides privacy against the public media and more generally the casual eavesdropper. Authentication contributes to controlling resources usage in an environment where such resources may be scarce.

To summarise, the challenges awaiting emergency telecommunication infrastructures are: rapid and scalable deployment, versatility in functionalities, interoperability and security.

\subsection{Stakes}

While telecommunications indubitably improve co-ordination among teams and institutions, the stakes go further than this operational standpoint and the possibility to mitigate casualties.

Studies [4] have demonstrated the correlation between effective disaster management and the economic impact on the country or region. This impact is two-fold: the direct consequence on the socio-economic activity and the impact on insurance contracts (rates increase, coverage decreases).

The earthquake that took place in Turkey in 1999 resulted in a loss of about two points of the GNP of Turkey during 5 years. Conversely, it is widely recognized that the efficient management of the Kobe disaster (Japan, 1995) made it possible to significantly restrain the negative impact on the city economy (Kobe was the largest commercial harbour in Japan port before the earthquake). During the September 11th terrorist attacks, several Manhattan-located financial institutions had to stop their activity because of telecommunication links being cut off [4].

For natural disasters, experts agree that the cost of these disasters is likely to increase because of environmental degradation (e.g. landslides happen more often due to deforestation), climate change, population growth (especially in the cities) and globalization [5]. It is also agreed that disasters affect more hardly developing countries, for their fragile economy is more exposed [6]. 
Finally, the impact of a disaster can unexpectedly take over the political scene. The 2007 forest fires in Greece and the associated perception on how the government managed the disaster had an impact on the elections. For disasters implying nuclear hazards, such as in Chernobyl (Ukraine, 1986), the political impacts on an international level are even more obvious.

\section{SATELLITE SYSTEMS FOR EMERGENCY TELECOMMUNICATIONS}

In the following paragraphs, we provide a brief description of today's satellite technologies and services. We also describe what-in our opinion-is the best positioning of satellite communications.

\subsection{Current satellite technologies}

Existing satellite technologies can be categorized according to their purposes: observation, navigation and telecommunication.

Observation satellites provide images of the Earth. Several technologies are used from infrared to Synthetic Aperture Radar images. These images are used for example to track forest fires or map the operation area, especially if the landscape has dramatically changed as a consequence of the disaster. Examples of observation satellites services are EUMETSAT, Spot, NOAA/POES and the Disaster Monitoring Constellation. Observation satellites depend on a fixed, ground infrastructure in order to collect and post-process data. Data is then made available to end users by means of regular terrestrial means. In case of disaster, such observation data should also be distributed to the co-ordination task forces and emergency centres by means of the emergency telecommunications.

Global Navigation Satellite Systems provide Earth terminals with accurate position information (longitude, latitude and altitude). Present systems are GPS and GLONASS. Galileo is the forthcoming European system.

Telecommunication satellites provide data broadcast and data communication services. Broadcast services include television and high-definition television and radio. Data communication services are further subdivided into narrowband (data rates below $1 \mathrm{Mb} / \mathrm{s}$ ) and broadband $(1 \mathrm{Mb} / \mathrm{s}$ and above). Besides the data rate, these systems present different capabilities in terms mobility (fixed, transportable or mobile users). Examples of narrowband satellite operators are: Globalstar (mobile), Inmarsat (fixed, mobile and transportable), Iridium (mobile) and Thuraya (mobile). Examples of broadband satellite operators are: Eutelsat, Hispasat, Intelsat and SES Astra.

Conventional communication links and resources might be saturated during disaster phases and it might be not be possible to complete a call even if that call is the concern of safety of life. In that way safety services shall have priority over any other services in order to be able to be processed whatever the crisis situation is.

In order to instate some priority level the ITU Radio Regulations encompass some safetyrelated provisions giving priority to (or exclusive usage of) distress and safety systems in a few Mobile Satellite Service sub-bands.

When selecting the right system, all these considerations must be integrated to the users' requirements in order to achieve a proper balance between service availability, performance and pricing. This latter aspect is covered in Section 7 since it deserves special attention.

\subsection{Role of satellite communications in emergency telecommunications}

Satellite systems display several properties crucial in the framework of emergency telecommunications. The satellites are - by definition-more resilient to disasters and damages. Their weakest point, as far as Earth disaster are concerned, being the gateways and network control centres (implementing redundancy discards this risk). Geostationary satellites provide a coverage which is sufficient to serve the operation field. For large disasters, only satellites are 
actually able to cover the whole scene and provide broadband services. The use of spot beams supports efficient management of the satellite capacity. There is currently an accepted trade-off between data rate and mobility which is rooted in the specifics of antenna technology and signal propagation in a mobile channel. For fixed and transportable systems, data rates of hundreds of $\mathrm{kb} / \mathrm{s}$ are possible, serving a variety of services. Mobile systems display on the other hand reduced data rate (several tens of $\mathrm{kb} / \mathrm{s}$ ) with the advantage of improved versatility in deployment. Still, current techniques and advances in digital communications give indications of the performance leverage expected for mobile technology, blurring the frontier with transportable terminals.

Finally, the regulation of the satellite related bands is already handled at an international level as opposed to analogue PMR for example. This is certainly a strong point in favour of quick deployment and it also helps to devise a pan-European system.

There are also drawbacks. Some of them are tightly bound to the physics of satellite transmissions, others relate to the business models of the various satellite industry actors. First of all, satellite transmissions often require line of sight. Indoor operations must then rely on gap filling. The data rates achievable through a satellite system are tightly linked to the size and directivity of the antenna. The higher the data rate, the larger the antenna and the more accuracy required for pointing. Finally, satellite capacity and equipment may be perceived as costly especially when the competition is harsh with other terrestrial telecommunication technologies.

Satellite communications have an important role to play in emergency telecommunications provided a correct coupling is found between terrestrial and satellite technologies. This vision is supported by the belief that the following areas are especially tailored for deployment of satellite-based solutions:

- Providing terminals with mobile and long haul capabilities for the first minutes/hours of the catastrophe.

- Trunking and backhauling $\mathrm{mb} / \mathrm{s}$ of data over large $(>100 \mathrm{~km})$ distances using satellite terminals deployed 'on the spot'.

- Providing temporary links for 'repairing' disconnected networks (either through predeployed satellite terminals or not) in order to convey critical traffic.

- Broadcasting of (possibly real time) data to large areas for example providing responders and co-ordination centres with up-to-date and detailed GIS (Geographical Data Systems) feeds.

- Providing location data.

- Providing observation data.

\section{INSTITUTIONAL BODIES AND INITIATIVES IN EUROPE}

Identification and discussion about technical gaps, future user requirements and policies is certainly a first step to effective disaster management support. The Integral Satellite Initiative (ISI) has a dedicated working group on the use of satellite communications for security issues. The aerospace and defense industries association of Europe (ASD Europe) has also set up a technical group in order to identify coming challenges on security, including the use of satellite communications. The Public Safety Communication Europe Forum (PSCEf) has similar activities with the unique advantage to group three communities: industry, research and users. These technical oriented initiatives have a political equivalent at the European Parliament called the cross party intra-group on civil protection.

From the standardization standpoint, different organizations and institutions are involved in emergency communications via satellite. In Europe, CEN, CENELEC and ETSI have standardising activities (EMTEL Special Committee, SES/SatEC working group) or are promoting work on the identification of standardization gaps for emergency communications via satellite. Project MESA is an international partnership between ETSI and TIA.

From the operational perspective, various organizations are involved in the co-ordination of disaster management at an international basis: the EC Monitoring and Information Centre, the 
UN Disaster Assessment and Coordination System, the NATO Euro-Atlantic Disaster Response Co-ordination Centre and their associated bodies: the European Community Humanitarian and office, the UN office for the co-ordination of humanitarian affairs and the NATO senior civil emergency planning committee. As such, these are primarily users of satellite communications.

In order to facilitate the use and deployment of communication services for disaster management several initiatives have been taken in the past: the Tampere Convention and the international charter for major disasters. The former eases the use and deployment of telecommunication equipment in countries requesting help. The latter sets up an effective framework for sharing satellite imagery upon disaster.

Finally, projects are/were funded by the European Commission and the ESA whose aims are to study satellite-enabled communication solutions to ease disaster and risk management. For instance the TANGO-FP6 project aims at developing a software platform which should optimise, both technically and cost wise, the allocation of satellite resources to GMES service providers including for crisis management and humanitarian aid purposes. Other examples of running or recently finalized projects are Wisecom, CHORIST, OASIS, STICK and SASS-2IP.

The following Section discusses another issue which is central to the massive use of satellite technology for emergency telecommunication: how to make it viable from a financial standpoint.

\section{FINANCIAL VIABILITY}

Satellite communications certainly play an important role in the provision of emergency telecommunication facilities. However, there is an associated challenge to tackle: how to guarantee the financial viability? In the following paragraphs, we list the difficulties related to achieving a suitable business model. Then, some directions are drafted in order to relief satellitebased emergency telecommunications from the economical pressure and secure the return on investment.

The first difficulty is related to the cost of satellite terminals. Because emergency situations can be seldom predicted and because rapidity of deployment is a key issue, there is a need to predeploy and possibly stock terminals in key areas. In addition to the investment required, it also calls for pro-active maintenance. Even unused, these terminals will suffer from depreciation. This unfortunate effect is further increased considering that often, the organizations involved in emergency response are not co-ordinating themselves for their investment policies.

The second difficulty is related to the price of satellite capacity and the complexity-for an operator - to rapidly re-distribute available capacity. Indeed, when a disaster occurs, the need for capacity is likely to increase drastically. The operator must be able to release capacity, while ensuring that running contractual agreements are not breached. A similar problem to terminal stocking exists with satellite capacity: it is economically unwise to book satellite capacity in the perspective of a future event which - by definition-yields an unknown return on investment.

The third difficulty is related to the way emergency responses are financed and organized. Non-governmental organizations (NGOs) are involved as first responders and are the major actors on the mid term. NGOs suffer from the decrease in charity donations. Additionally, most fundraising campaigns are organized after the disaster (pro-active fundraising campaign are less successful), making it difficult to massively invest in advanced equipments.

In order to tackle these difficulties, we advocate that emergency telecommunication terminals should (a) incorporate both terrestrial and satellite technologies and (b) be used for daily operations and emergency situations. On the one hand, this improves the conditions for achieving a favourable return on investment. On the other hand, it also guarantees that emergency responders will be acquainted with their communication facilities, not discovering its specificities on the spot when subject to various stressing conditions. This solution may also contribute to improve daily operations since satellite communications could be used where terrestrial coverage is poor or absent. 
Regarding satellite capacity, there are three possible approaches. We refer to them as preemption, coexistence and dedicated schemes.

The pre-emption scheme relies on dual-purpose satellite payloads, where capacity is partly dedicated to - say commercial use - partly to civil protection purposes. Upon emergency situation, resources are pre-empted from the commercial share according to a pre-established agreement and billing plan. In this context, the term pre-emptive deals with the ability of the emergency telecommunication system to borrow resources from the others active systems not being used for the emergency purpose. This goal may be achieved, for example, allowing the emergency systems to reserve channels during the crisis period. The pre-emption model relies on the presence of operational networks and resources availability in the crisis area. It also requires employing technologyindependent interfaces and pre-emption procedures commonly agreed among satellite operators and institutional bodies. Finally, it requires paying for the capacity reservation and/or for the marginally used capacity during regular operations and the more massive use when the need arises.

Unlike the pre-emption scheme, a coexistence scheme means that the emergency system should be allowed to take resources from another system without interfering in its normal operations. In this case the availability of the supporter network's services is not necessary. However, it is mandatory to have advanced functions (e.g. cognitive radio) on both terminals and emergency system gateway. Moreover, communication systems without infrastructures (mesh networks) represent the only possible choice when the networks with infrastructure are not available during a crisis (e.g. earthquake or wide catastrophic events). The possibility to deploy broadband services using this coexistence scheme is subject to further study. With respect to that, one might imagine a system where narrowband services use the coexistence scheme and broadband services rely on resource pre-emption. The coexistence scheme can also be deployed during the first hours before switching to the pre-emption scheme.

The third approach is by far more radical and consists in the deployment of a dedicated civil protection payload. The coverage achieved with a geostationary system is a driver to share capacity and costs between different regions and governments, and get to a better usage pattern with improved economics. Coupled to support of daily operations, it lays the foundation for an effective return on investment perspective. For a dedicated system, there is the risk related to the procurement processes, which for very good reasons requires competitive bids. However, if the market is small, or respectively if there are limited budgets available only, there might be only limited competition and a key question is whether the market can survive without multiple competitors. Prices of the equipments may grow uncontrolled and also, the uncertainty in market demand and size is a barrier to investing into solutions for bringing costs down.

\section{FUTURE DEVELOPMENTS FOR PROMOTING SATELLITE-BASED EMERGENCY TELECOMMUNICATIONS}

Considering the previous observations, the following needs and directions for research and development are identified:

- Developing a satisfying financing plan integrating the cost of equipment/capacity, the need for quasi-instant deployment of capacity/terminals and the limited financial means available.

- Developing interoperability among terrestrial technologies (wireless LAN, cellular infrastructures) in order to ease the integration of a satellite component. This is especially true for commercial systems (i.e. GSM communication), which are often preferred by the emergency users, just because they are used to them. A special focus must also be put on the interconnection of legacy analogue PMR technology considering the significant amount of systems that are deployed (e.g. Radio over IP).

- Developing user transparent support for hybrid communications where-based on the situation - a terminal is able to select the most appropriate transmission technology or to balance the traffic load among multiple technologies.

- Developing coding and modulation techniques making possible the efficient coexistence of multiple signals on the same channel. 
- Developing innovative operational approaches to optimise the use of existing satellite capacity in emergency situations through the deployment of adequate satellite solutions and the allocation of communication resources whenever and wherever needed.

Taking account of the fact that infrastructure for safety communications is undersized in Europe and that some remote zones do remain non-covered, a satellite system might enhance availability of safety communications links and would still be operational in case the terrestrial infrastructure is damaged or saturated. Although mobile-satellite services require complementary ground components in order to ensure signal availability and continuity in urban areas, it is worth to be mentioned that satellite has the advantage of providing coverage of remote areas for which incumbent terrestrial cellular technology is very expensive to deploy.

More generally, the emergency field lacks ICT-enabled tools. Finding a satisfying match between the harsh field constraints and the consequences (streamlining of practices, need for additional/ updated training) of introducing high technology on the field is probably the next major challenge.

\section{CONCLUSION}

We addressed the challenges of setting up satellite-based emergency communication facilities during a disaster from technical, financial and organizational standpoints.

According to the ideas developed in this contribution, we will conclude with a list of what we consider as inaccurate if not flawed popular wisdom:

- 'Emergency communications address disaster management'. As indicated before, best training and operation practices call for the use of the same equipment regardless of the situation (daily emergencies or disasters).

- 'Emergency communications are focused on the emergency response phase'. Because one key aspect is deployment delay, a careful planning is required possibly requiring pre-deployment.

- 'Emergency communication equipments are like others'. Contrarily to the current trends on the telecommunication market, the design and development of ITC-enabled emergency communication must be user driven and not technology pushed.

- 'It is only a technology issue'. While it cannot be denied that there are technological locks to tackle, major challenges remain from financial and political standpoints.

- 'There is no need for dedicated telecommunication solutions, public telephony networks with proper service level agreements are sufficient'. While public telephony networks often do provide valuable services, they do not fully meet the robustness, infrastructure-less and fast deployment requirements of emergency communications.

- 'The higher the bit rate, the better'. Not always. In the first minutes of the response phase, it is crucial to have immediate access to an affordable communication technology, even though it only provides several tens of kbit/s. Aiming to first minute broadband communication solutions will certainly impair these two core requirements.

\section{REFERENCES}

1. Satellite Earth Stations and Systems (SES); Satellite Emergency Communications. Overview of present satellite emergency communications resources. ETSI Technical Report, TR 00285 v1.1.1, 2008.

2. Barnier M. For a European Civil Protection Force: Europe aid, 2006.

3. Emergency Communications (EMTEL). Requirements for communication between authorities/organizations during emergencies. ETSI Technical Specification, TS 102181 v1.2.1, 2008.

4. Large-scale disasters: lessons learned, OECD, April 2004.

5. World disasters report 2007-focus on Discrimination, International Federation of Red Cross and Red Crescent Societies, 2007.

6. Toya H, Skidmore M. Economic development and the impacts of natural disasters. Economics Letters 2007; 94(1):20-25. 


\section{AUTHORS' BIOGRAPHIES}

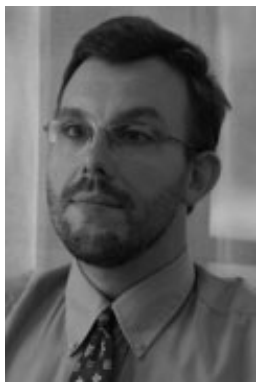

Laurent Franck has a PhD degree in Telecommunications from Telecom ParisTech in 2001 . Since 2007 he is with Telecom Bretagne (Toulouse site) where he teaches and conducts research on satellite networking. His main research interests are in the development of satellite based emergency communications. Laurent is also a volunteer first-aid worker for the French Red Cross.

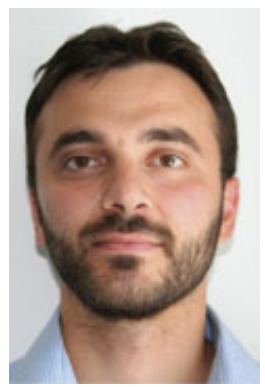

Matteo Berioli received a Laurea degree in Electronic Engineering, and the $\mathrm{PhD}$ degree in Information Engineering from the University of Perugia (Italy), both with honors, in 2001 and 2005 respectively. Since 2002 he is with the German Aerospace Center (DLR), where since 2008 he is leading the Networking and Protocols Group of the Digital Networks Dept. in the Institute of Communications and Navigation. His main research activities are in the area of IP-based satellite networks; key research issues include QoS and protocol analysis, cross-layer techniques and packetlayer coding. Since 2006 he is also working as expert for the European Telecommunications Standards Institute (ETSI) in the area of broadband satellite multimedia; he has been the chairman of the satellite working group of the PSCE Forum (Public Safety Communications Europe Forum). Matteo Berioli is author/ co-author of around 50 papers that appeared in international journals and conference proceedings. Matteo Berioli was the general project manager of the WISECOM project, and he has been working in several European (EU and ESA) research projects with leading roles, often coordinating technical activities and satellite system life trials.

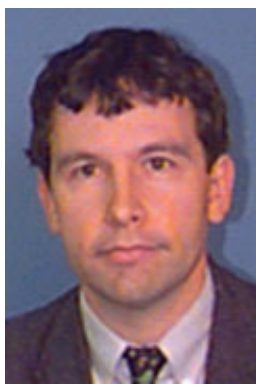

Philippe Boutry is working in the Telecommunications Satellites Directorate, currently in charge of Telecom System Business Development. He is involved in the definition of system of systems architectures and coordinates the use of satcoms for Security and Public Safety applications. He has more than 25 years of professional experience in the space industry. At Astrium since 1991, he assumed the function of project manager in different business units prior to joining the Telecommunications System department in 2001.

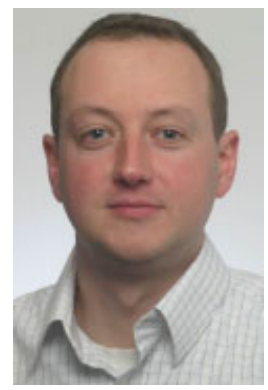

Guy Harles has an Engineering degree (Dipl.Ing) from the RWTH Aachen (Germany) in 1996 and an MBA from the Open University (UK) in 2008. Since 1996 he is with SES ASTRA (Luxembourg), where he worked in Ground Engineering before moving to Strategic Business Development in 2007. His main engineering interests were in the development of advanced solutions for satellite operations and satellite communication systems, while now he is focusing on strategic planning and strategy execution. 


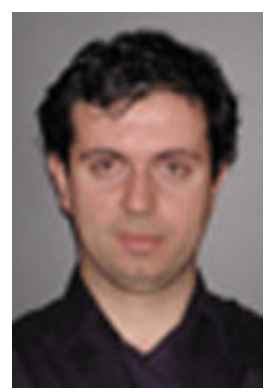

Luca Simone Ronga (luca.ronga@cnit.it) [IEEE S'89-M'94-SM'04] received his MS degree in Electronic Engineering in 1994 and his $\mathrm{PhD}$ degree in Telecommunications in 1998 from the University of Florence, Italy.

In 1997 joined the International Computer Science Institute of Berkeley, California, as a visiting scientist. In 1998 obtained a post-doc position in the Engineering faculty of the University of Florence. In 1999, he joined the Italian National Consortium for Telecommunications (CNIT), where he is currently head of research. Since 1997 he has authored several funded projects in various Telecommunications fields. In 1997 he led a national research group of the project 'Integration of Multimedia Services on Satellite Heterogeneous Networks' which successfully developed a Software Defined Radio satellite modem prototype. In 2001 he has been leader of the international research group Access Network Aspects for the COST272 European action 'Packet Oriented Service Delivery via Satellite'. In 2001 he was involved as WP leader in the DAVID programme 'Small Missions for Science and Technology'. He has been the project leader for the national project FormSat 'Development of CNIT academic learning satellite system on Italian Objective 1 Regions' in 2003. In 2004 he was involved in the EU SatNEx 'Satellite Communications Network of Excellence' as leader of an international group on 'Cognitive Radio'. Since 2007 he is responsible for the CNIT satellite network operations and the scientific activities on the platform which is currently one of the largest $\mathrm{Ka}$ band satellite networks in Europe.

$\mathrm{He}$ is a member of NATO task force IST-077 RTG-035 devoted to coordination of Cognitive Radio research activities among coalition partners. He is also 'Rapporteur' for technical standard 'MAMES' DTS/ SES-00310 in the ETSI group SES-SatEC (Satellite for Emergency Communications) and Official CNIT delegate at ETSI, participating to ETSI SES-SatEC task force. He conducts research activity and project management in various Telecommunications areas, mainly in the satellite and terrestrial wireless fields. He has authored over 70 papers published in books, international journals and conference proceedings. He has been editor of EURASIP Newsletter. His interests range from satellite communications to Software Defined Radio and Cognitive Radio techniques.

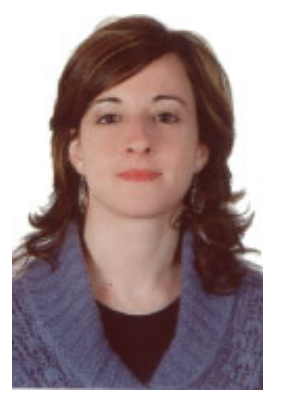

Rosalba Suffritti received the MS degree in Telecommunications Engineering from the University of Florence, Italy, in 2006, and, her PhD in 'Computer science, Multimedia and Telecommunications' from the University of Florence, Italy, in 2010. Her research activity focuses on advanced topics in satellite communications: cooperative strategies in mobile environments, satellite emergency communications and cognitive radio technologies. She is a Student IEEE member and member of ETSI SES- SatEC (Satellite Earth Stations and Systems - Satellite Emergency Communications) working group which carries out the activity of standardization on satellite emergency communications. She is the author of about 20 papers in international journals and proceedings of international conferences.

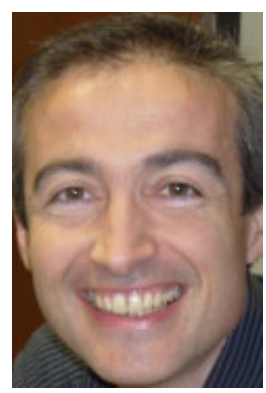

Laurent Thomasson has over 14 years of experience in the Space Industry. Based in Toulouse, France, he is currently at the Head of Telecom Marketing and R\&D Coordination in the Telecom Marketing and Institutional Relations Division of Astrium.

He was previously responsible for system projects and business development within the Astrium Telecom System Group.

He works in close relation with Satellite Operators, the European Commission, the European and National Space Agencies to understand and support the development of satcom services (broadband, mobile, broadcast applications), as well as to consolidate satcom product development priorities.

Prior to joining Astrium, he worked at Aerospatiale Les Mureaux as Telecom system engineer for performance assessment of Global Navigation Satellite System constellations (GNSS2), and before that on remote sensing activities in the Centre

d'Etudes Spatiales de la Biosphère (processing and analysis of Synthetic Aperture Radar data).

He graduated from ENST, Paris, a French leading Engineering School in the field of Telecommunication Technologies. 